\title{
Measuring Respiration Rate Based on Android
}

\author{
I Kadek Eman Giyana Mahardika, Torib Hamzah, Triana Rahmawati, Liliek Soetjiatie \\ Department of Electromedical Engineering Poltekkes Kemenkes Surabaya \\ Surabaya, Indonesia \\ giyanamahardika31@gmail.com, trbhamzah@gmail.com, triana.tekmed@gmail.com
}

\begin{abstract}
Respiratory rate measurement tool is a technique used to determine the number of respiratory activities a person every minute. In the classification of the number of breathing per minute which can be divided into three groups, namely the so-called eupnea/normal, above average breathing called tachypnea, while below the average so-called bradypnea. This method is highly dependent on the concentration of the mind and senses actor sensitivity measurement and observation. Therefore, human nature is easy to forget, tired and bored, so now developed a method of measurement or observation of respiratory rate electronically. In this study, respiratory rate measurement making use flex sensor by placing the sensor in the patient's stomach and will detect the curvature of the patient's stomach. Results from the patient's respiratory displayed on the LCD Character and android using HC-05 Bluetooth as the media sender. The results of the measurement data of the 10 respondents indicated the average - average error of $3.2 \%$. After testing and data collection can be concluded that the appliance is eligible to use because it is still within the tolerance range of $10 \%$.
\end{abstract}

Keywords - Respiratory rate, Flex Sensor, HC-05 Bluetooth, Android

\section{INTRODUCTION}

The respiratory rate measurement tool is a technique used to determine the number of respiratory activities a person every minute. respiratory rate measuring devices can be used to monitor the amount of breathing and can show abnormalities in patients. In the classification of the number of breathing per minute which can be divided into three groups, namely the socalled eupnea/normal, above average breathing called tachypnea, while below the average so-called bradypnea[1],

Respiratory rate is important physiological parameters that help to provide important information about the health status of the patient, especially the human respiratory system. The frequency of abnormal breathing can indicate a variety of conditions including respiratory disease and systemic disorders including cardiovascular disorders and acidosis. Respiratory rate is also a parameter commonly used in routine patient monitoring to detect early disease and a decrease in clinical conditions. This measurement is important even in patients who are vulnerable, for example, for premature infants (neonates), infants under 6 months (infants) and parents. For example, respiratory rate can be used as an indicator to detect asthma. Monitoring human breathing during sleep provides a role in the diagnosis and treatment of sleep apnoea,[2],

Breathing (respiration) is a process that causes more oxygen into the lungs and reaches the cells of the body, as well as the process (in the reverse direction) which causes the carbon dioxide out of the body through the nose or mouth. Breathing is a dual process, namely the exchange of gases in the respiratory tissues and in the lungs - pulmonary or respiratory outside. Oxygen is required as a reactant in the formation of energy in the cells of the body, while carbon dioxide is the result of the remainder should be discarded because they are toxic to the body.

Respiratory rate is defined as the total number of breath, or breathing cycle, which occurs every minute. The simplest method for determining the rate of breathing is to calculate directly (manually) moving up and down the chest wall or to hear the sound of the breath (breathing sounds) through a stethoscope. This method is highly dependent on the concentration of the mind and senses actors sensitivity measurement and observation. Therefore human nature is easy to forget, tired and bored, so now developed a method of measurement and observation of respiratory rate electronically[3],

In 2011, Fahmi Ahmad Fatkudin Farisandi and make tool "Patient Diagnostic Indicators Portable Equipped with Normal / Abnormal (Parameter rate of breathing)" are displayed on the seven segment display. Next Dian Novia Fatmawati (2015) enhance the module by displaying a graph on a PC display. Furthermore Farah Disk Bestari (2016) makes the tool "Monitoring Heart Rate, Respiration Rate is equipped with temperature sensors to the personal computer through Bluetooth (Parameters Respiration Rate)". Sensor for respiratory frequency used is condenser mic sensor so that if the state of a noisy environment will affect the monitoring process. That same year Mikki Fahrizi Muharrahman also make the tool "Based Monitoring Respiration rate of the PC (Personal Computer) equipped with Volume Breathing". The respiratory sensor on the device using pressure sensors MPX5100 GP. The weakness in this tool, a tool used to measure respiratory rate sensor is less accurate, so the authors suggest to use flow transducer sensor[4]. Furthermore Siska Diah Pangestu (2017) made "Breathing Frequency Measurement with Temperature Sensor to Personal 
Computer". Respiratory sensor uses pressure sensors Force Sensing Resistor (FSR) and a temperature sensor using LM35 sensor. Sending data to the PC using the HC-11 and there is a data storage in the form of a pdf file. The weakness in this tool is to use less precise sensors, resulting in difficult data collection. Laras (2018) makes the module "Measuring Instrument with Indicator Apnea Breathing rate Microcontroller Based Atmega1284". Respiration data display in the form of figures and graphs on the TFT LCD. H5V5 respiration sensor uses sensors and sensor placement in mount piece and there is indicators apnea.

Based on the background of the above problems, in this moment I would like to improve shortcomings of existing tools to make "Measure Tool The rate of breathing-Based Android" using flex sensors that will be placed in the patient's abdomen to measure breathing rate of patients as well as complementary instruments with a view android to allow a user in patient monitoring. There are indicators of normal and abnormal status information with third bradypnea criteria, eupnea, tachypnea to allow a user to conclude the diagnosis.

\section{MATERIALS AND METHODS}

\section{A. Experimental Setup}

Data collection was performed on 10 people aged 20-22 years and each - each person is measured 5 times each person.

\section{1) Materials and Tools}

This study uses flex sensors \pm 2.2 with $20 \mathrm{~K}$ ohm resistance change from baseline resistance of about $25 \mathrm{k}$ ohms. Flex sensors placed in the abdominal area to detect when the breath abdominal diaphragm. Components used to use as a nano Arduino microcontroller module, Differential Amplifier circuit as the conversion of resistance into voltage.

\section{2) Experiment}

In this study, researchers conducted measurements of the output of the differential circuit with an oscilloscope. Researchers take measurements on a sample number of respondents by random breath with an appeal that is manual measurement tool.

\section{B. Block diagram and flowchart}

When the switch is in the ON position then the entire series will receive a voltage from the battery. Flex sensors will detect changes in the curvature of the patient's stomach when breathing. The output of flex sensor will go into series conditioner analog signal and then output the sensor is processed by the circuit microcontroller to get the value of respiratory rate per minute is then displayed on the LCD characters and transmitted using Bluetooth module HC- 05 for display on Android as a value in respiratory rate per minute is accompanied by a description of breathing normal, bradypnea, tachypnea.

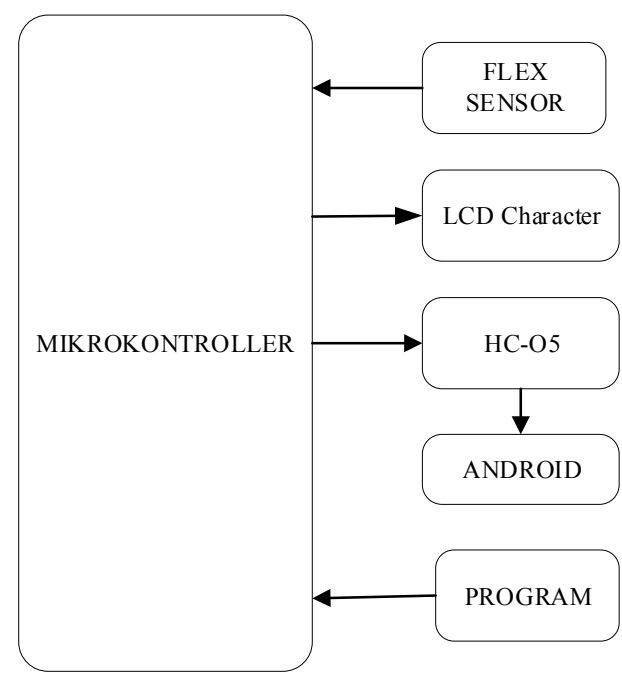

Fig 1. Block Diagram Circuit

When the start button is pressed the sensor will begin to detect the movement of the patient's stomach. The results of sensor readings are then processed by the microcontroller to get the data value of respiratory rate in 30 seconds and then the results will be displayed on the LCD in the form of respiratory rate.

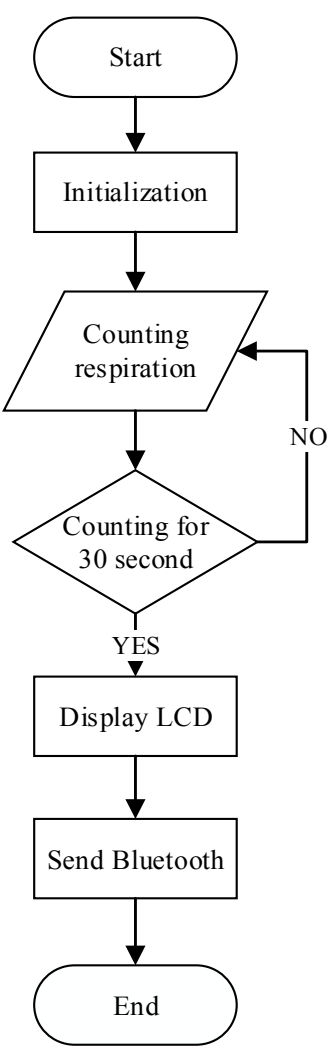

Fig 2. The Flowchart Modul 
Android is already connected via Bluetooth when pressed start the data processed in the microcontroller will be sent directly to Android, On android will display the value of respiratory rate every 30 seconds and displays the form eupnea classification respiratory rate (normal), bradypnea, tachypnea.

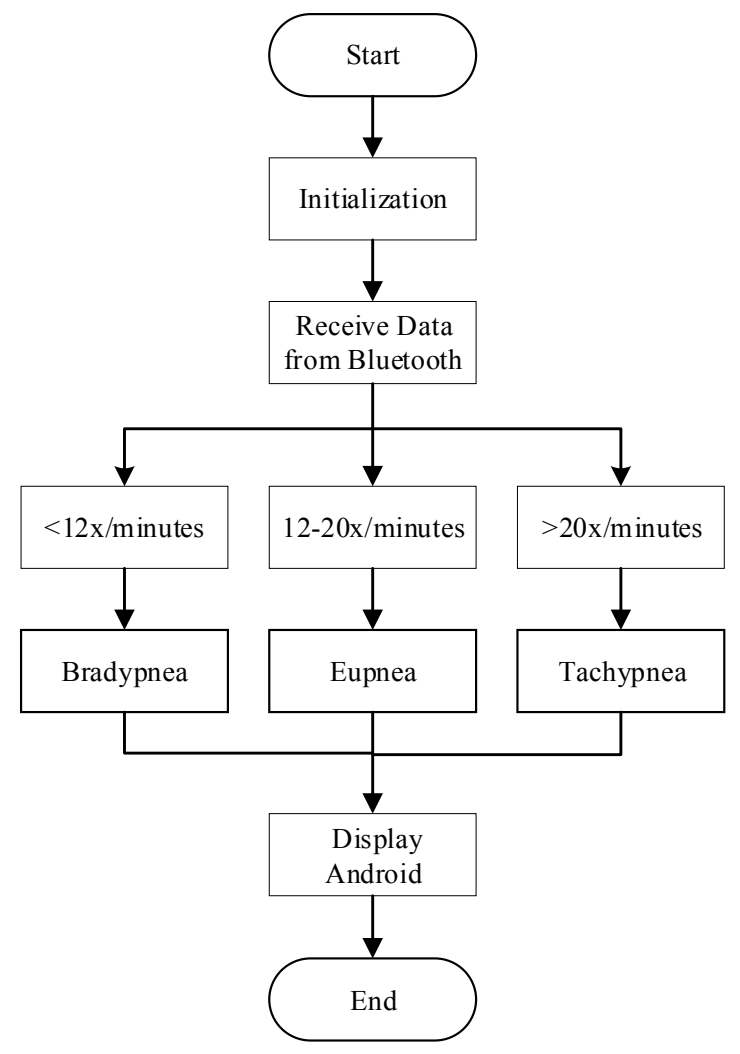

Fig 3. The Flowchart Android

C. Circuit

1) Voltage divider

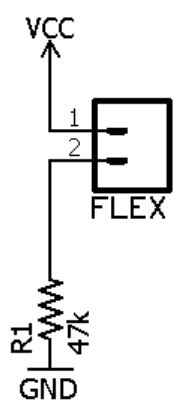

Fig 4. Voltage divider

The flex sensor is a sensor that when curved will experience a change in resistance. So that when the flex sensor is curved it will create division voltage Vout of change depending on the resistance generated when the sensor flexes arch.

\section{Amplifier and Filter Circuit}

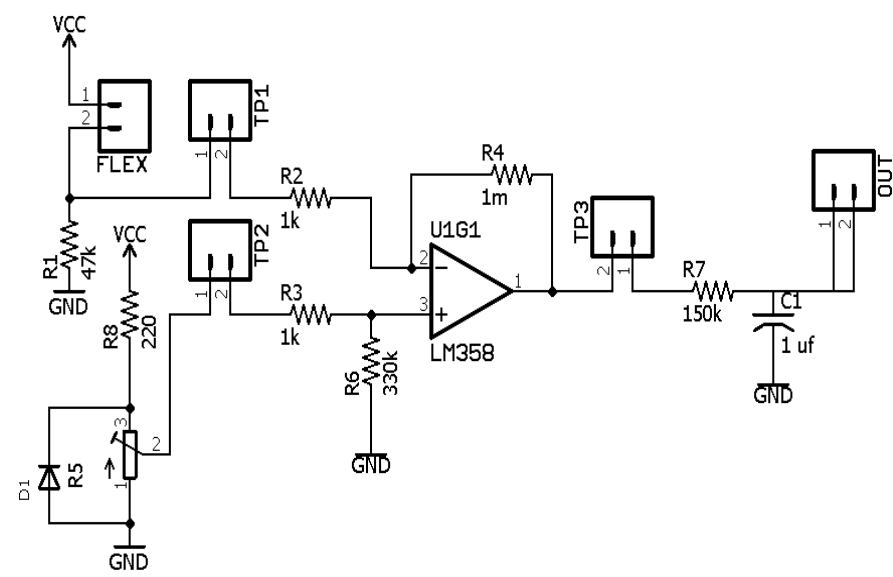

Fig 5. Filter and Amplifier Circuit

Requires a 5V DC supply voltage for LM358 IC supply, the difference amplifier circuit serves to disaccord voltages $\mathrm{V} 1$ and V2 of the output voltage divider circuit. After the voltage will be strengthened, the output of the difference circuit will be filtered to avoid noise during sensor flex curved.

\section{RESULTS AND ANALYSIS}

In this research, making breathing is done through the installation of flex sensors on the patient's stomach and respiratory calculations done manually.

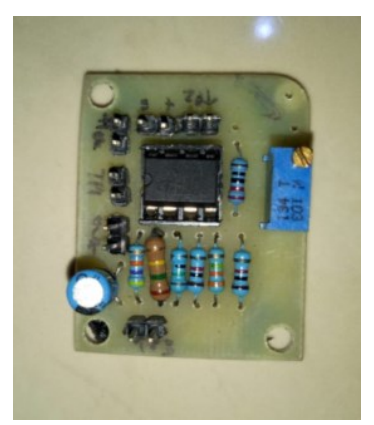

Fig 6. Filter and Amplifier Circuit

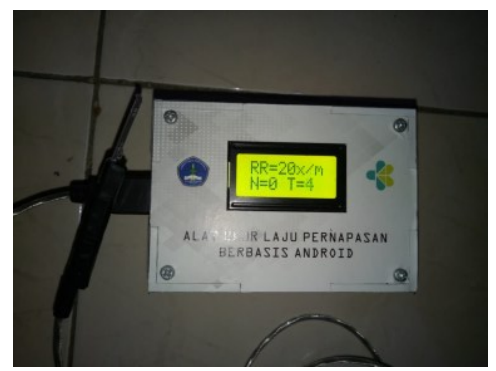

Fig 7. Forms Module 


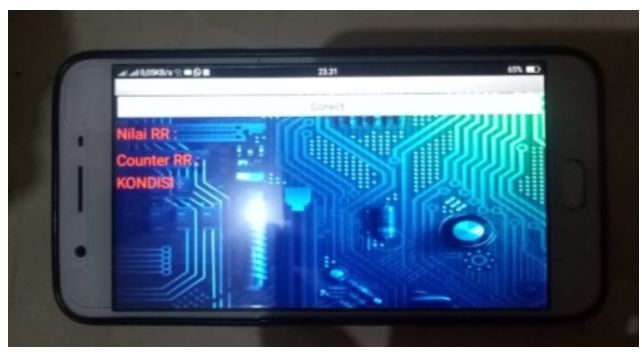

Fig 8. Display Android

\section{1) The Respiration Rate Design}

Flex curved sensor at the time will make the Vout voltage divider will change according to the curvature of the flex sensors. Difference amplifier circuit serves to differentiate between voltages V1 and V2, and the voltage will be boosted after going filter boosted voltage so that the voltage generated is not noise. the output of the difference circuit will go into the series microcontroller to be processed and the results will be displayed on the LCD Character, and Bluetooth is connected to the microcontroller will make deliveries to your android device for display on android.

\section{2) The Listing Program for Arduino Respiration Rate}

The output voltage of the circuit will enter the Difference Amplifier A0 foot Arduino with the following programs:

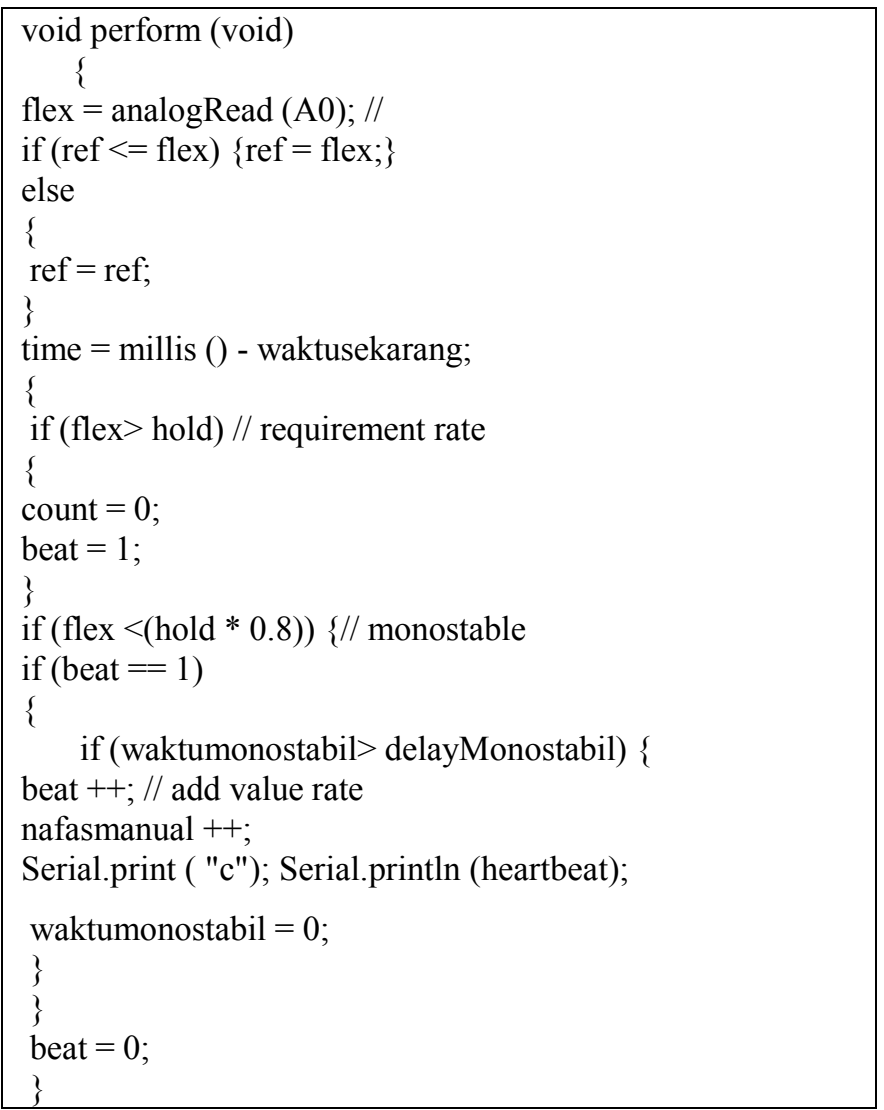

\}

waktusekarangRR = millis () ;

$\operatorname{detak} 1=0$

\}

if (waktumonostabil <60000) \{waktumonostabil = waktumonostabil $+6 ;\}$

\section{3) Listing Program Value Rate of Breathing}

Listing Program to calculate the total value of the breathing within 30 seconds, the result of the calculation will in time respiratory 2 after the running time for 30 seconds and the Bluetooth data transmission on android.

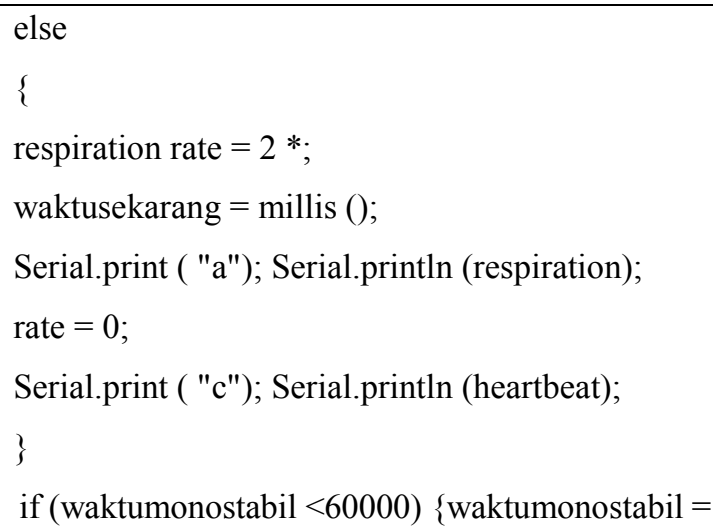

if $($ waktumonostabil $<60000)$ \{waktumonostabil $=$ waktumonostabil $+10 ;\}\}$

4) Program At MIT APP

a) Block Selection Bluetooth

Blocks above is a program to open the list of names and Bluetooth will be selected to connect the connection. Bluetooth on select should already have been done pairing with android.

\section{when ListPicker1 $>$.BeforePicking \\ do set ListPicker1 7 . Elements $\nabla$ to 'BluetoothClient1 $~$. AddressesAndNames *}

Fig 9. Bluetooth Election Program

\section{b) Bluetooth Connection Program}

On the block describes the status of the Bluetooth connection to android. After selecting the Bluetooth name will be connected, then android will be directly connected to the module and writing android Connect on the display will change to Disconnect. 


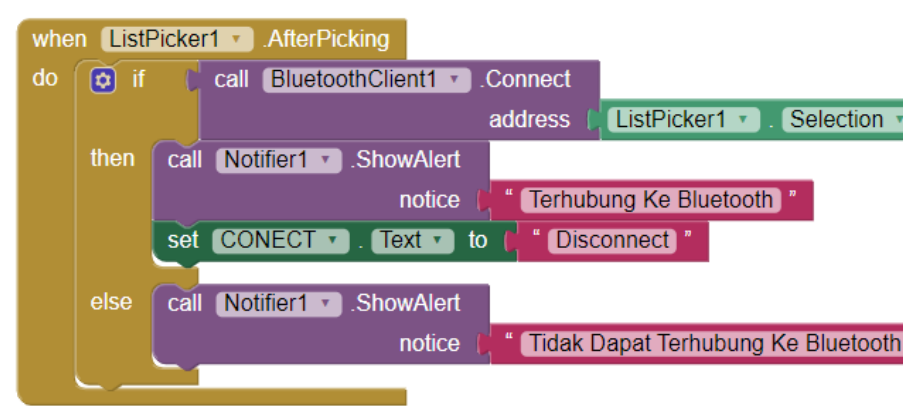

Fig 10. Bluetooth Connection Program

c) Breathing Value Display Program on Android

On the block is explained show breath value in 30 seconds sent by the module. This block also features 3 Events, wherein when breathing within 30 seconds, 12-20x per minute meal will display the normal condition/eupnea. When breath $<12 \mathrm{x}$ per minute displays Bradipnea conditions, while breath $>20 \mathrm{x}$ per minute displays Tachypnoea conditions. There is an alarm on this block, an alarm will sound when the breath condition is below average $(<12 \mathrm{x}$ per minute) or above-average breath $(>$ $20 x$ per minute).

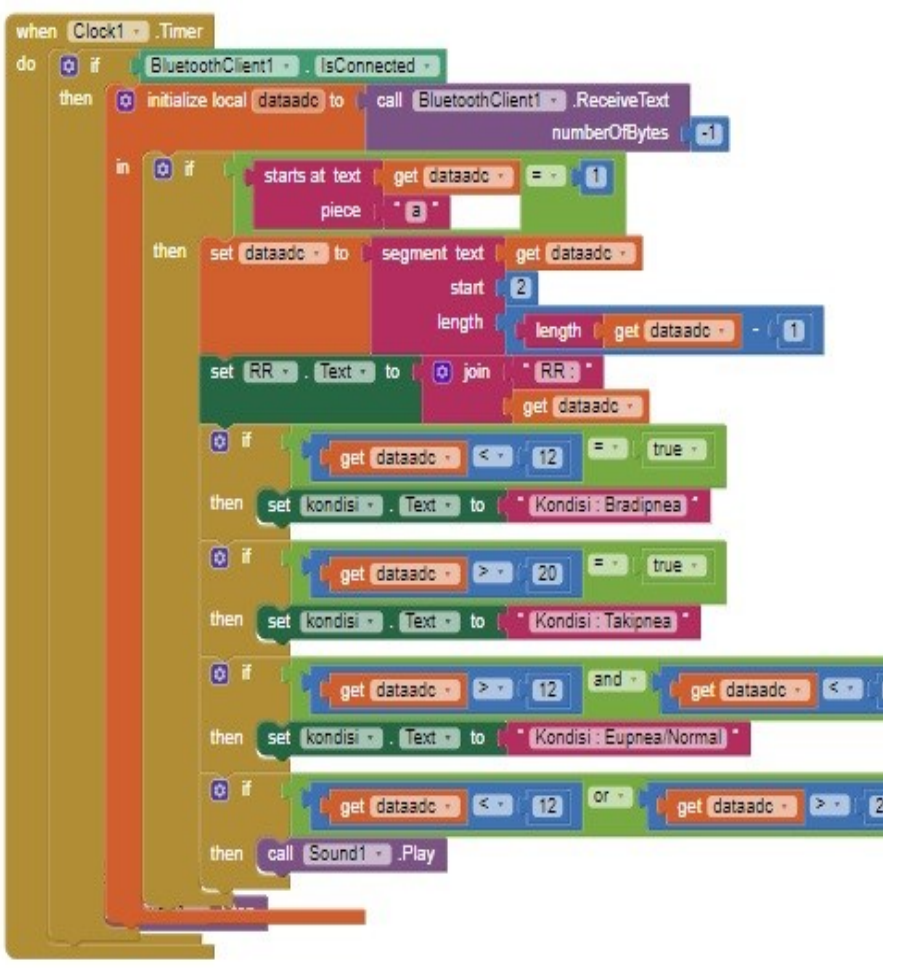

Fig 11. Breathing Value Program Shown on Android

\section{5) Test Results Point}

Fig.12 Measurements at Test Point 1 (TP1) of the voltage divider circuit when the condition of breathing amplitude that produced very small. This is because the signal is not amplified so that the amplitude of the resulting very small.

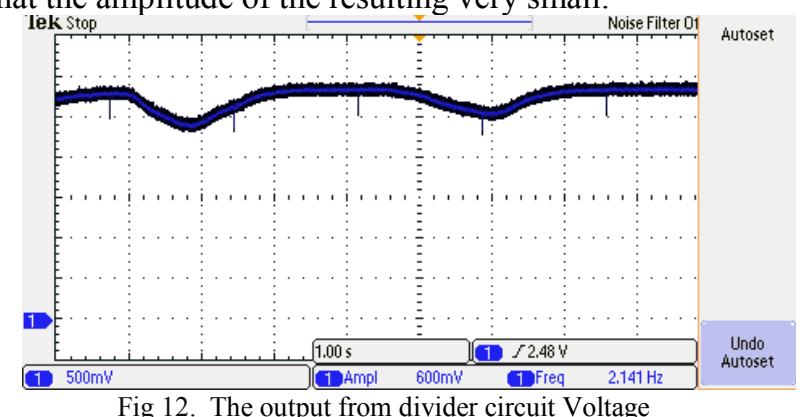

Fig 13 Measurements on test point 3 (TP3) of Difference Amplifier circuit breathing conditions at the time, amplitude value has increased. The measured value is equal to 3.27 volts, the signal conditions there are still many nois.

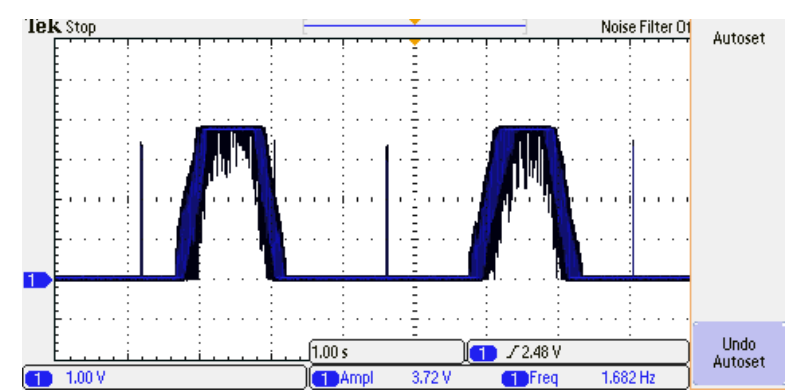

Fig 13. Output Differential Amplifier circuit

6) Respiratory Measurement with comparison Tool Manual Counting

The results of data collection can be on the show as follows:

TABLE I. Results of Measurement ERror Parameter Value RESPIRATION WITH MANUAL TOOLS

\begin{tabular}{ccc} 
NO & RESPONDENTS & ERROR $(\%)$ \\
\hline 1. & 1 & 2.5 \\
\hline 2. & 2 & 2.2 \\
\hline 3. & 3 & 5.0 \\
\hline 4. & 4 & 5.4 \\
\hline 5. & 5 & 2.8 \\
\hline 6. & 6 & 3.0 \\
\hline 7. & 7 & 2.7 \\
\hline 8. & 8 & 2.7 \\
\hline 9. & 9 & 2.6 \\
\hline 10. & 10 & 3.0 \\
\hline AVERAGE & & 3.2
\end{tabular}




\section{Discussion}

From the results of data collection by comparing the comparator and module can be error amounted at $5.4 \%$ in the fourth respondent and value with the smallest error in the respondent 2 is equal to $2.2 \%$, with the average - average error of $3.2 \%$.

\section{CONCLUSION}

Measurement has been made Android-Based Respiratory rate by using nano Arduino microcontroller module. Can be made to the appearance of the android software. Measurement has been made Android-Based Respiratory rate used to value average error of $3.2 \%$.

\section{REFERENCE}

[1] T. H. A. Kholiq, "Design and Development of Respiratory Rate Calculators Patients with Breath Disorders," Int. J. Sci. Res., vol. 7, no. 9, pp. 815-817, 2018.

[2] S. Das, "Development of A Respiration Rate Meter - A Low-Cost Design Approach," Heal. Informatics - An Int. J., vol. 2, no. 2, pp. 9-16, 2013.

[3] W. E. Sonata and Wildian, "Rancang Bangun Alat Pengukur Suhu Tubuh Dengan Tampilan Digital dan Keluaran Suara Berbasis Mikrokontroller AVR AT MEGA 8535," J. Fis. Unand, vol. 4, no. 4, pp. 32-43, 2015.

[4] Mikki Fahrizi Muharrahman, "Monitoring Laju Pernapasan Berbasis PC ( Personal Computer ) dilengkapi dengan Volume Pernapasan," pp. 1-8, 2016. 